\title{
Erratum to: Causes for early and late surgical re-intervention after radial head arthroplasty
}

\author{
Pierre Laumonerie $^{1}$ - David Ancelin ${ }^{1} \cdot$ Nicolas Reina $^{1}$ - Meagan E. Tibbo ${ }^{2}$. \\ Panagiotis Kerezoudis $^{2} \cdot$ Stephanie Delclaux $^{1} \cdot$ Nicolas Bonnevialle $^{1} \cdot$ Pierre Mansat $^{1}$
}

Published online: 27 May 2017

(C) SICOT aisbl 2017

Erratum to: International Orthopaedics (SICOT)

DOI: $10.1007 / \mathbf{s 0 0 2 6 4 - 0 1 7 - 3 4 9 6 - 0}$

Figure 2 in the original publication contains a few mistakes. The radial head prosthesis designs in Fig. 2a, b are Evolutive ${ }^{\circledR}$ (Aston Medical, Saint-Etienne, France) and Guepar® (Aston Medical, Saint Etienne France) respectively. Below is the appropriate correction:
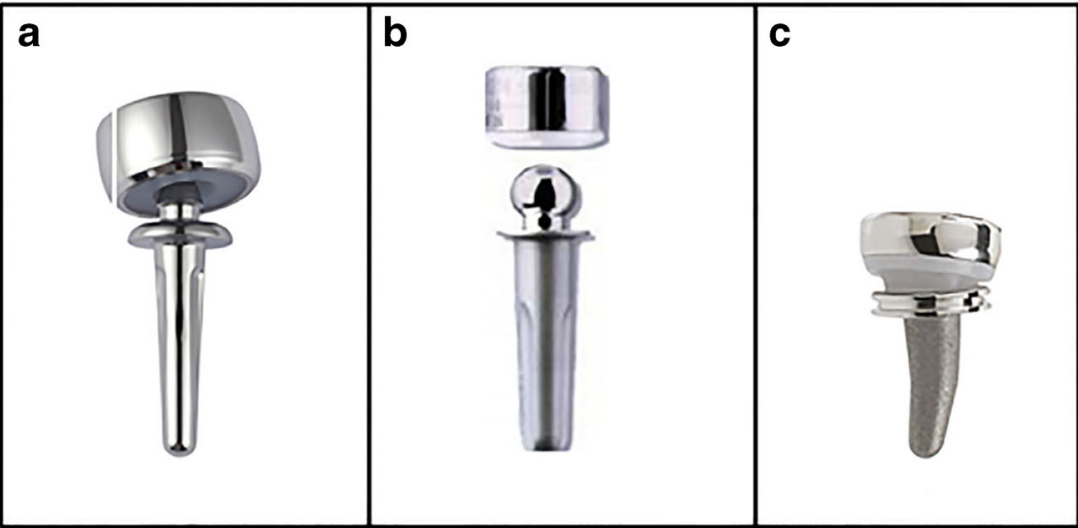

Fig. 2 Three bipolar radial head prostheses: Evolutive ${ }^{\circledR}$ (a) (Aston Medical, Saint-Etienne, France), and Guepar® (b) (Aston Medical, Saint-Etienne, France) are implants with a long, cemented stems anchored beyond the neck; the rHead® Recon implant (c) (Stryker-Small Bone

Innovation, Morrisville, Pennsylvania, USA) has a short, press-fit stem for high neck fixation and possible cementation if initial stability is not obtained

The online version of the original article can be found at http://dx.doi.org/ $10.1007 / \mathrm{s} 00264-017-3496-0$

Pierre Laumonerie

laumonerie.pierre@hotmail.fr

1 Hôpital Pierre-Paul Riquet, Place du Docteur Baylac, 31059 Toulouse, France

2 Mayo Clinic, Rochester, MN 55905, USA 